\title{
Vinte anos de cinema brasileiro: compreendendo a cultura cinematográfica no Brasil no século XXI
}

\author{
Laura Loguercio Cánepa' \\ https://orcid.org/0000-0003-3248-599x \\ I - Universidade Anhembi Morumbi. \\ São Paulo (SP), Brasil.
}

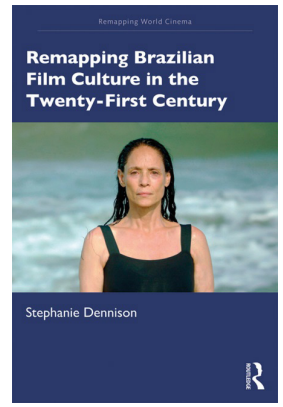

DENNISON, S.

Remapping Brazilian film culture

Resumo: Remapping Brazilian film culture in the twenty-first century, de Stephanie Dennison, reflete sobre as transformações da cultura cinematográfica no Brasil nos últimos vinte anos, observando o papel desempenhado pelo cinema nacional no período que marcou a ascensão e o declínio da "Era Lula". Seu olhar pautado pelos estudos culturais e por um profundo conhecimento do cinema brasileiro embasam essa análise retrospectiva que contribui para a compreensão das conquistas artísticas, econômicas e culturais obtidas em quase duas décadas de políticas públicas voltadas para o audiovisual.

Palavras-chave: Brasil; século XXI; cinema brasileiro; cultura cinematográfica; estudos culturais.

Abstract: Twenty years of brazilian cinema: understanding cinematographic culture in Brasil in the 21st century - Stephanie Dennison's Remapping 
Brazilian film culture in the twenty-first century reflects on the transformations of film culture in Brazil in the last twenty years, observing the role played by the national cinema in the period marking the rise and decline of "Lula Era". Dennison's perspective, based on Cultural Studies and in-depth knowledge of the discussions on brazilian cinema underlies this retrospective analysis that contributes to the understanding of the artistic, economic and cultural achievements obtained in almost two decades of public policies focused on audiovisual.

Keywords: Brazil; XXI century; brazilian cinema; film culture; cultural studies.

Stephanie Dennison é pesquisadora de Estudos Brasileiros e coordenadora do Center for World Cinemas da Universidade de Leeds, no Reino Unido. Desde o começo dos anos 2000, ela já publicou diversos trabalhos sobre o cinema brasileiro, entre os quais Brazilian Popular Cinema (com Lisa Shaw, em 2004) e Brazilian National Cinema (também com Lisa Shaw, em 2007). Em 2018, Iançou, junto com Maite Conde, a coletânea Paulo Emilio Salles Gomes - On Brazil and Global Cinema, primeira publicação em língua inglesa a reunir textos fundamentais do crítico brasileiro, como Uma Situação Colonial? (1960) e Cinema: Trajetórias no Subdesenvolvimento (1973). O mais recente trabalho de Dennison sobre o cinema brasileiro, Remapping Brazilian Film Culture In The Twenty-First Century, publicado pela editora Routledge, em 2019 (dentro da coleção Remapping World Cinema: Regional Tensions and Global Transformations), articula discussões centrais para a compreensão da situação atual do cinema nacional, o que inclui análises da indústria audiovisual brasileira, dos circuitos de consumo e recepção dos filmes, e também de obras cinematográficas dos últimos vinte anos.

Na Introdução de Remapping Brazilian Film Culture In The Twenty-First Century, Dennison explica que sua ideia de cultura cinematográfica baseia-se nos trabaIhos de Janet Harbord, Graeme Turner e Paulo Emílio Salles Gomes (2019, p. 2), e consiste na análise das práticas que moldam o fluxo dos filmes, incluindo estratégias de produção, marketing, festivais de cinema, crítica, canais de distribuição e locais de exibição. Segundo a autora, a cultura cinematográfica brasileira do século XXI deve ser lida como parte de um fenômeno mais amplo articulado globalmente (que inclui dinâmicas relacionadas a financiamentos locais e internacionais; transformações tecnológicas; relações com o cinema mundial), cujo funcionamento interno é necessariamente distinto e, portanto, merecedor da atenção particular dos estudiosos do cinema mundial.

Dennison revela que sua inspiração veio, originalmente, de uma curiosidade a respeito do impacto do governo do Partido dos Trabalhadores na 
política e na produção cultural do Brasil. Segundo ela, "quando eu propus a ideia do livro para Routledge em 2014, percebia que muita coisa havia mudado ao longo do século XXI em relação à cultura cinematográfica no país" (DENNISON, 2020, p. 3). Porém, continua Dennison, "essa afirmação ainda é verdadeira, mas de maneiras que eu não poderia ter imaginado na época, dada a profunda crise econômica na qual o Brasil está mergulhado, e dado o fim abrupto do governo do Partido dos Trabalhadores" (2020, p. 3).

Assim, a autora explica que o livro seguiu o planejamento original -mapear as principais mudanças das primeiras duas décadas do século XXI, incluindo os últimos debates culturais no Brasil sobre o financiamento de filmes e práticas de distribuição; o impacto das políticas de diversidade na indústria cinematográfica brasileira; a recepção e circulação de filmes brasileiros no circuito internacional de festivais de cinema; o impacto de novos modos de exibição nas práticas de visualidade; a representação do Brasil por cineastas estrangeiros; e o papel da Rede Globo no mais recente boom de produção - mas também examina "o impacto, na produção cultural, da mudança brusca de direção política em nível nacional experimentada após o golpe parlamentar de 2016 que ocasionou o impeachment da presidente Dilma Rousseff" (DENNISON, 2019, p. 1).

Dennison destaca o fato de que o cinema ocupa um espaço menos proeminente nas discussões em torno das mídias no Brasil quando comparado à televisão ou, mais recentemente, às redes sociais, mas que busca examinar a cultura cinematográfica evitando duas armadilhas que consistiriam em presumir que: “a) os únicos filmes sendo vistos ou discutidos do público brasileiro são sucessos de bilheteria e b) esses sucessos emprestam pouco à compreensão da cultura brasileira" (2019, p. 2). Nesse sentido, a análise da autora transita com a mesma facilidade entre filmes realizados em comunidades indígenas (desde o projeto Vídeo nas Aldeias, iniciado nos anos 1980, até filmes de enorme impacto sobre o tema indígena, como Martírio, de Vincent Carelli, Tatiana Almeida e Ernesto de Carvalho, 2016) e blockbusters nacionais como Tropa de Elite 2 (José Padilha, 2011). O resultado é uma compreensão realmente ampla da cultura cinematográfica brasileira nos vinte primeiros anos do século XXI.

O livro é dividido em duas partes. A parte I tem seis capítulos, nos quais se percebe, ao mesmo tempo, o profundo conhecimento da autora sobre a história do cinema brasileiro e também seu particular interesse pelo ganho 
de visibilidade das minorias e grupos subalternizados, num período marcado por políticas de inclusão desenvolvidas na sociedade brasileira como um todo - inlusive no cinema. Os capítulos são os seguintes: 1. Fazendo filmes no Brasil do século XXI; 2. Engajando o público em casa e no exterior; 3. Mulheres e cultura cinematográfica no Brasil; 4. Comunidades LGBTQ do Brasil e cultura cinematográfica; 5. O cinema afro-brasileiro no século XXI; 6. Exibindo nas telas a experiência indígena no Brasil.

Entre os destaques da primeira parte do livro, além da visão ampla sobre o cinema brasileiro dos anos 2000, ressalte-se que a preocupação da autora de informar aos leitores estrangeiros sobre o Brasil faz com que o trabalho ultrapasse facilmente a reflexão sobre nossos últimos vinte anos, e ganhe em vários momentos um notável poder de síntese sobre toda a história do cinema brasileiro em sua relação com a cultura e a história do país. É assim quando Dennison examina o fenômeno de filmes religiosos como Os Dez Mandamentos: O Filme (Alexandre Avancini, 2016), produzido pela Igreja Universal do Reino de Deus a partir de uma minissérie exibida pela TV Record (2019, p. 40-42), ou quando relaciona as comédias bem-sucedidas da Globo Filmes, como Minha Mãe é Uma Peça 2 (César Rodrigues, 2016, estrelada pelo comediante Paulo Gustavo no papel-título), às chanchadas brasileiras dos anos 1950 (2019, p. 40). Fora das grandes produções relacionadas à televisão, Dennison também discute, por exemplo, temas como o papel da ANCINE no desenvolvimento de políticas de produção audiovisual no Brasil; a inserção transnacional de diretores brasileiros como Walter Salles, José Padilha, Maria Augusta Ramos e Karim Ainouz; a participação fundamental de Gilberto Gil no Ministério da Cultura durante o Governo Lula; a emergência de figuras vindas de grupos periféricos, como a MC Linn da Quebrada, entre muitas outras informações e discussões que formam um panorama precioso da cultura audiovisual brasileira do século XXI.

Na parte II, Dennison trabalha com análises de filmes a partir das quais reflete sobre temas como a insegurança urbana; a relação de nosso cinema com os clichês a respeito do Brasil; a tematização de nossa relação com a miséria; a atualização da ideia da cordialidade na cultura brasileira. Nesta seção do livro, são quatro capítulos: 7. Cinema e segurança pública: o fenômeno Tropa de Elite (2007-2011); 8. O Olhar Estrangeiro (2005) de Lúcia Murat e a representação do Brasil nas telas estrangeiras; 9. A esperança brota do lixo: Trash (2014) e a estética do lixo; 10. Uma vista cordial ao Nordeste do Brasil: Aquarius, de Kleber Mendonça Filho (2016). 
$\mathrm{Na}$ análise dos filmes, a sensibilidade para perceber os movimentos mais amplos a partir de exemplos singulares permanece como uma marca de um trabalho fundamentado nos estudos culturais e na observação das dinâmicas operadas pelos filmes em sua circulação na sociedade, desde a produção até a exibição. Chama a atenção a escolha de filmes que dialogam diretamente, mas de diferentes maneiras, com o cinema internacional, o que coloca a discussão sobre o cinema brasileiro em um circuito não autocentrado. A autora escolhe, assim, filmes que tiveram impacto internacional em festivais (como Tropa de Elite, no Festival de Berlim, e Aquarius, em Cannes); a coprodução internacional Trash: a esperança vem do lixo (Stephen Daldry; Christian Duurvoort, 2014); e também discute o olhar do cinema estrangeiro sobre o Brasil a partir do documentário de Lucia Murat baseado no livro do pesquisador brasileiro Tunico Amancio, O Brasil dos Gringos. Nota-se também, nas análises, a compreensão de autores fundamentais para o pensamento sobre a cultura brasileira (como Sérgio Buarque de Hollanda, Nelson Rodrigues e Glauber Rocha) e ao mesmo tempo a menção a inúmeros pesquisadores e analistas culturais contemporâneos brasileiros e estrangeiros.

No epílogo, escrito no primeiro semestre de 2019, Dennison também faz uma reflexão sobre o que poderia aguardar o cinema brasileiro com o início do governo de extrema-direita que então acabava de assumir o poder. Segundo ela:

embora os filmes comerciais e de arte continuem a ser lançados, emprestando superficialmente uma sensação de continuidade da cultura do cinema brasileiro, a triste realidade é que como resultado da "reestruturação" dos mecanismos de apoio à produção cultural, o cinema brasileiro corre o risco de uma paralisação (2019, p. 198).

Mas, segundo ela:

como cada novo dia parece trazer uma nova notícia de cair o queixo relacionada ao atual governo, o "projeto Bolsonaro" provavelmente fornecerá ampla inspiração narrativa para a cultura do cinema brasileiro nos próximos anos - supondo, é claro que os cineastas sejam capazes de fazer filmes com um mínimo de apoio financeiro do Estado, e livres de censura (2019, p. 199).

No conjunto, o livro reúne uma impressionante quantidade de informações obtidas em fontes acadêmicas, artísticas, jornalísticas, críticas e 
governamentais, em uma obra atualizada com a produção nacional não apenas no cinema, mas também nos estudos desenvolvidos nas universidades, na produção crítica e no pujante e variado universo dos festivais e mostras de cinema brasileiros. A leitura de Remapping Brazilian film culture in the twenty-first century nos conduz necessariamente a reflexões sobre a história do cinema brasileiro, mas também sobre as conquistas e retrocessos que vivemos nos últimos vinte anos na experiência social, cultural e política nacional. Trata-se, portanto, de uma obra de referência que merece tradução para o português, o que sem dúvida intensificará o diálogo com um público mais amplo dentro do Brasil.

Laura Loguercio Canepa é professora e coordenadora do Programa de Pós-Graduação em Comunicação da Universidade Anhembi Morumbi, em São Paulo.

laura_canepa@yahoo.com.br

\section{Referências}

AMÂNCIO, A. C. T. O Brasil dos gringos: imagens no cinema. Rio de Janeiro: Intertexto, 2000.

CONDE, M.; DENNISON, S. (Eds.). Paulo Emílio Salles Gomes: On Brazil and Global Cinema. University of Wales Press, 2019.

DENNISON, S. Remapping Brazilian film culture in the twenty-first century. Londres: Routledge, 2019.

DENNISON, S.; SHAW, L. Popular cinema in Brazil. Manchester University Press, 2004. 2007. Brazilian national cinema. London: Routledge, 2007.

HARBORD, J. Film cultures. London: Sage, 2002

TURNER, G. Editor's Introduction. In: TURNER, G. (ed). The film cultures reader. London and New York: Routledge, 2002. p. 1-10.

Resenha recebida em 09/11/2020 e aprovada em 05/01/2021. 